\title{
A comparison of pregnancy dating methods commonly used in South Africa: A prospective study
}

L Geerts, MB ChB, MRCOG, BSc (Hons)(Hum Genet), Dip (Fetal Med)(UK); E Poggenpoel, BTech, BSc (Hons)(Hum Genet), MSc (Reprod Biol); G Theron, MB ChB, BSc Hons (Epidemiology), FCOG, MMed, MD

Department of Obstetrics and Gynaecology, Tygerberg Hospital and Faculty of Medicine and Health Sciences, Stellenbosch University, Cape Town, South Africa

Corresponding author: L Geerts (lgeerts@sun.ac.za)

\begin{abstract}
Background. Pregnancy dating in the South African public healthcare setting is mainly based on clinical assessment. However, the accuracy of this approach is unknown.

Aim. To compare the accuracy of different pregnancy dating methods.

Methods. We performed a prospective comparison of 2 ultrasound policies involving consecutive low-risk women in a midwife clinic in the Metro East region, Cape Town, Western Cape. Information on the last menstrual period (LMP), the 1st symphysis-to-fundal height measurement (FH) and average gestation by ultrasonographic (US) fetal biometry was recorded. Five dating methods: LMP, FH, US and their combinations, were assessed against the actual day of delivery (ADD). The main outcome measures were: (i) the days between the ADD and estimated date of delivery in pregnancies where spontaneous labour occurred and the baby had a normal birth weight; (ii) the incidence of gestational age-related outcomes; and (iii) the influence of clinical variables on dating discrepancies.

Results. A total of 1342 pregnancies were analysed. The accuracy of dating was similar for certain and uncertain LMP. FH was less accurate with increasing obesity. US-based dating was most accurate (for $85 \%$ of predictions within 14 days) and similarly accurate at 20 - 24 weeks and at $>24$ weeks. US reduced the number of assumed pre-and post-term deliveries and, in addition, was better at detecting small-forgestational age infants $(p<0.001)$.

Conclusion. Pregnancy dating by US, including those in more advanced pregnancies than currently permitted, is recommended since all non-ultrasound-based estimations of gestational age were considerably less accurate.
\end{abstract}

S Afr Med J 2013;103(8):552-556. DOI:10.7196/SAMJ.6751

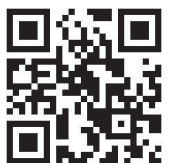

Optimal management of pregnancy relies on accurate assessment of the gestational age (GA) of the fetus; which can be determined by the history of the last menstrual period (LMP), clinical estimation of the 1st symphysis-to-fundal height measurement $(\mathrm{FH})$ or ultrasonographic fetal biometry. However, many women fail to recall their LMP accurately. ${ }^{[1]}$ Moreover, pregnancy duration and fertile period are highly variable, even for women with regular cycles. ${ }^{[1]} \mathrm{FH}$ suffers from poor reproducibility and high variability due to maternal and fetal factors; ${ }^{[2-4]}$ its accuracy for dating has not been extensively studied $^{[5-7]}$ and requires FH dating charts (rather than growth charts). Ultrasonography (US) in the 1st, or early 2 nd trimester, is highly reproducible ${ }^{[8]}$ and widely used for dating, since early biological variability of fetal biometry is minimal. ${ }^{[9]}$ In the past, certain LMP was used for dating as long as the GA was within 7,10 or 14 days of the estimate of GA by US, ${ }^{[10]}$ but now 1st, or 2 nd trimester, US is increasingly recommended as the single dating method because of its smaller error rate. ${ }^{[1,11,12]}$

The accuracy of dating GA by US in late pregnancy is less well studied, but may be clinically valuable. ${ }^{[13,14]}$ The current policy in the Western Cape Province of South Africa (SA) provides for a routine US examination between $18-23$ weeks of the clinically estimated GA for low-risk pregnancies since this reduces the number of presumptive post- and pre-term deliveries as well as the number of referrals to a higher level of care for suspected deviations in fetal growth. ${ }^{[15]}$ The approximately $34 \%$ of women who typically present at $>23$ weeks $^{[16]}$ do not routinely receive US. Pregnancy dating is based on a pragmatic guideline incorporating information from the LMP, $\mathrm{FH}$ and early US (if available). ${ }^{[17]}$ The accuracy of this guideline and the clinical value of late US-based GA dating have not been assessed. Our aim was to determine the accuracy of the different dating methods, and of their combinations, since they are currently widely used in SA. We performed a prospective study that compared the current US policy with a policy that included a routine booking scan.

\section{Objectives}

(i) Determine the accuracy of US in predicting the actual date of delivery (ADD), (ii) compare the incidence of GA-related outcomes and (iii) assess the influence of clinical variables on discrepancies between the dating methods.

\section{Methods}

The main study, described elsewhere, ${ }^{[16]}$ was a prospective, interventional, before-and-after study in low-risk women ( $n=750$ in each study arm) initiating antenatal care in 2 midwife-led clinics in the Metro East region, Cape Town, Western Cape. The study was approved by the Committee for Human Research, University of Stellenbosch (project no. N07/04/080) and a waiver of individual informed consent was granted.

During the 1st period (October 2007 - January 2008, comprising the control group), women received a routine US at $18-23$ weeks GA, determined by clinical estimation based on a combination of the date of the LMP and FH. Additional scans were permitted, as per current policy, only for specified clinical indications. During the 2nd period, (February - April 2008, comprising the study group), a 'booking US scan' was obtained for all women within 7 days of their booking, regardless of GA. Singleton pregnancies continuing to $>24$ weeks were included if information was available for $\geq 1$ dating method if $\mathrm{ADD}$ was known and $\geq 2$ if ADD was not. We excluded pregnancies 
with obvious abnormal findings on US (e.g. anomaly, oligo- or polyhydramnios and asymmetric growth).

We determined the GA according to LMP, FH, US and 2 combinations of these methods, which we termed the clinical and final GA. Only FH measurements obtained prior to the US were considered for the analysis. FH-based GA was calculated by plotting the 1st standardised FH measurement on the 50th centile of the local reference range for $\mathrm{FH}$ growth. ${ }^{[4]}$ In line with routine local practice, US-based GA was determined from published growth charts by calculating the average GA from multiple biometric variables, provided they were concordant and the fetus and liquor appeared normal on scan. ${ }^{[16]}$

The clinical GA was calculated by comparing the LMP-based GA and FH-based GA and refuting the LMP-based GA when the LMP was uncertain or the difference was greater than accepted tolerance intervals (of 3 or 4 weeks when the fundus was below or above the umbilicus, respectively). ${ }^{[17]}$

The final GA was determined from all available information, according to a local standardised guideline. The LMP-based GA and US-based GA were compared in cases where US biometry was available, refuting the LMP-based GA when the LMP was uncertain or the difference was greater than accepted tolerance intervals ( $>2$ standard deviations (SDs) before 16 weeks; $>2$ weeks at $16-24$ weeks ${ }^{[17]}$ and $>3$ weeks after 24 weeks). If no US was performed during the pregnancy, the clinical GA was deemed to be the final GA.

We determined pregnancy outcomes from medical records. Postterm was defined as delivery occurring $\geq 14$ days after the estimated date of delivery (EDD) calculated according to the final GA, local policy being to deliver electively at 42 completed weeks. Pre-term was defined as delivery before 37 completed weeks. Small- and large-forgestational age (SGA and LGA, respectively) were defined as birth weight (BW) $<10$ th centile or $>90$ th centile, respectively. ${ }^{[18}$

In women with spontaneous onset of labour who delivered an infant with a BW $\geq 2500 \mathrm{~g}$, the 5 dating methods were compared in terms of mean signed difference \pm SD and absolute number of days \pm SD between EDD and ADD (indicating systematic error, bias and precision, respectively). We analysed the influence of clinical variables - such as age, parity, body mass index (BMI), uterine size and duration of amenorrhoea at booking - on the absolute differences between LMP-based GA, FH-based GA and US-based GA in pregnancies for which $\geq 2$ dating methods were available. Percentages of (assumed) post-term or pre-term deliveries, SGA and LGA infants were compared between subgroups according to the timing of the US.

Data were analysed with SPSS (version 16) and Epi Info (version 3.5.1). Continuous variables were analysed with Student's $t$-test if the distribution was normal, otherwise with Mann-Whitney-U or KruskalWallis tests. Associations of variables were determined using Spearman correlational analysis. Discrete data was analysed using a chi-square test. Tests were two-tailed and considered significant when $p<0.05$.

\section{Results}

Of the original 1500 women, 1342 were suitable for this analysis (666 in the control group and 676 in the study group). The following were excluded: twins $(n=17)$, prenatally detected fetal anomaly ( $n=9)$, early pregnancy loss $(n=18)$, asymmetric fetal biometry on 1st US $(n=5)$, later confirmed as not pregnant $(n=13)$, and dating information not available $(n=30)$ or insufficient $(n=66)$. The mean age was 25.3 $(\mathrm{SD} \pm 5.4)$ years; the mean BMI was $26.2(\mathrm{SD} \pm 6.0) \mathrm{kg} / \mathrm{m}^{2}$; and $23 \%$ of women were obese (Table 1). By best clinical estimate, $61.3 \%$ booked before 24 weeks. The majority of women reported certain LMP dates (56\%) while $21.9 \%$ were uncertain. The change in policy increased exposure to any US from $62.5 \%$ to $88.9 \%$ of women. Exposure to the 1 st US at $<18$ weeks rose from $6.8 \%$ to $37.3 \%$, at $<24$ weeks from $55.0 \%$ to $65.1 \%$, and at $>24$ weeks from $7.2 \%$ to $23.8 \%(p<0.001)$. The LMP and FH were concordant within accepted tolerance intervals in 450/647 women (69.6\%). Differences between LMP-based and FH-based GA were smaller with lower BMI $(p=0.009)$ and smaller FH $(p<0.001)$ but were not affected by whether the LMP was reported as certain or not.

US contributed to final dating in 1017 (75.8\%) women, confirming the LMP in 362 (35.6\%) but refuting it in 455 (44.7\%) pregnancies. Differences between the LMP-based and US-based GA were smaller with earlier US $(p<0.001)$ and if the LMP was certain $(p<0.001)$ or compatible with FH $(p<0.005)$. The difference between US-based and FH-based GA increased with BMI (from mean 4.4, SD \pm 16.0 days for BMI $<25 \mathrm{~kg} / \mathrm{m}^{2}$ to mean 11.1, SD \pm 15.3 days for BMI $\left.>35 \mathrm{~kg} / \mathrm{m}^{2}, p=0.001\right)$. Large differences occurred more often in heavier women (Fig. 1) and large overestimations of $>3$ weeks were more common than underestimations (113 v. 23 women, $p<0.001$; odds ratio (OR) 5.85, 95\% confidence interval (CI) 3.60 - 9.57).

Table 1. Descriptive data of the GA dating methods

\begin{tabular}{|c|c|c|}
\hline & & $\begin{array}{l}\text { Total } \\
N(\%)\end{array}$ \\
\hline Age (years), mean $\pm \mathrm{SD}$ & $25.30 \pm 5.4$ & 1342 \\
\hline Gravidity $(n)$, median $(95 \%$ CI) & $2(0-4)$ & 1342 \\
\hline Parity $(n)$, median $(95 \%$ CI) & $0(0-3)$ & 1342 \\
\hline BMI $\left(\mathrm{kg} / \mathrm{m}^{2}\right)$, mean \pm SD & $26.2 \pm 6.0$ & 1341 \\
\hline Birth weight $(\mathrm{g})$, mean $\pm \mathrm{SD}$ & $3040.4 \pm 559.5$ & $1182(88.1)$ \\
\hline \multicolumn{3}{|l|}{$\begin{array}{l}\text { GA dating information (days), } \\
\text { median }(95 \% \mathrm{CI})\end{array}$} \\
\hline LMP-based GA at booking & $125(54-221)$ & $1047(78.0)$ \\
\hline 1st FH-based GA & $168(126-238)$ & $875(65.2)$ \\
\hline Clinical GA & $147(62-231)$ & $1270(94.6)$ \\
\hline LMP-based & - & $850(63.3)$ \\
\hline FH-based & - & $420(31.3)$ \\
\hline US-based GA at US & $143(63-218)$ & $1017(75.8)$ \\
\hline US $<168$ days & - & $806(60.1)$ \\
\hline Final GA at delivery & $276(239-300)$ & $1185(88.3)$ \\
\hline LMP-based & - & $534(39.8)$ \\
\hline + Early US & - & $310(23.1)$ \\
\hline + Late US & - & $52(3.9)$ \\
\hline + FH, no US & - & $130(9.7)$ \\
\hline no FH, no US & - & $42(3.1)$ \\
\hline US-based & - & $655(48.8)$ \\
\hline Early US, no LMP & - & $146(10.9)$ \\
\hline Early US, refuting LMP & - & $350(26.1)$ \\
\hline Late US, no LMP & - & $54(4.0)$ \\
\hline Late US, refuting LMP & - & $105(7.8)$ \\
\hline FH-based & - & $153(11.4)$ \\
\hline No US, incompatible LMP & - & $58(4.3)$ \\
\hline No US, no LMP & - & $95(7.1)$ \\
\hline $\begin{array}{l}\mathrm{GA}=\text { gestational age; } \mathrm{SD}=\text { standard deviation } \\
\text { mass index; } \mathrm{LMP}=\text { last menstrual period; } \mathrm{FH}\end{array}$ & $\begin{array}{l}I=\text { confidence inter } \\
\text { undal height; } \mathrm{US}=\mathrm{u}\end{array}$ & $\begin{array}{l}\text { 1; BMI }=\text { body } \\
\text { rasound. }\end{array}$ \\
\hline
\end{tabular}


The discrepancy between the clinical and US-based GA increased with age $(p=0.02)$, gravidity $(p=0.05)$ and 1 st $\mathrm{FH}(p<0.001)$ and was smallest with a clinical GA between 16 - 24 weeks.

Outcomes, defined according to the final GA at delivery, were analysed in all women with known ADD and BW and stratified according to US exposure (Table 2). It appeared that pre-or post-term deliveries and LGA infants occurred far more frequently in women who were not scanned than those who were ( $p=0.03, p<0.001$ and $p<0.01$; respectively) and SGA-infants were picked up more often in women who were scanned $<24$ weeks than in those scanned later or not at all $(p<0.001)$.

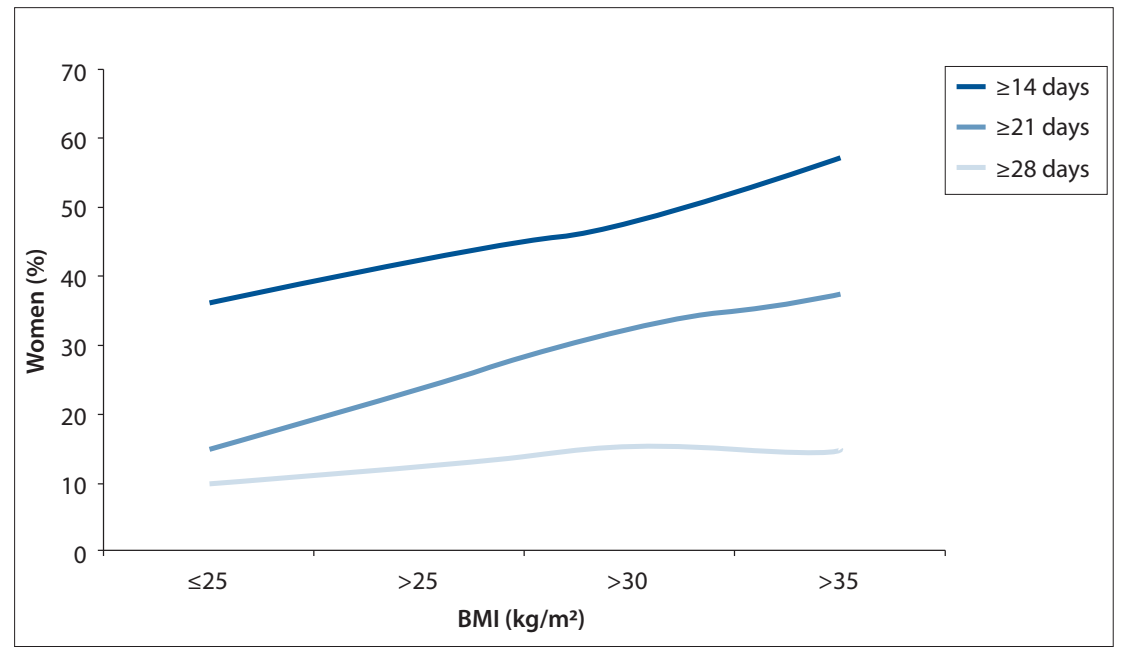

Fig. 1. Percentage of women with large differences between $G A$ according to US or $F H$, for different BMI categories. (For BMI $>30 \mathrm{~kg} / \mathrm{m}^{2} v$. $\leq 25 \mathrm{~kg} / \mathrm{m}^{2}$ at $\geq 14$ days, $\mathrm{p}<0.05$; for BMI $>25 \mathrm{~kg} / \mathrm{m}^{2} v . \leq 25 \mathrm{~kg} / \mathrm{m}^{2}$ at $\geq 21$ days, $\mathrm{p}<0.01$.)
The accuracy of ADD prediction was assessed in $875 / 1342$ women after the following exclusions: elective deliveries $(n=170)$, lost to follow up $(n=157)$, BW <2 $500 \mathrm{~g}(n=140)$. All dating methods performed better with early presentation and assessment, and worse with earlier delivery and lower BW, but were hardly affected by maternal characteristics and certainty of the LMP as recorded in the patient's notes (data not shown). Median signed differences between ADD and all EDD were small but had wide CIs: 3 days for LMP (95\% CI -35 - 57), 0 days for $\mathrm{FH}$ (95\% CI - 35 - 32), 3 days for US (95\% CI $-11-21)$ and 3 days for final GA (95\% CI -17 - 27). Absolute differences were smallest for US compared with LMP, FH and clinical GA (median 7 days; 95\% CI 1 - 46; $p<0.001$ ) and largest for LMP compared with all other methods (median 12 days; 95\% CI 1 - 64; $p<0.001)$. This was mostly notable when LMP was uncertain (median 15 days; 95\% CI 1 - 73) or incompatible with FH (median 33 days; 95\% CI 1 - 135) and for FH (median 13 days; 95\% CI 1 - 39), especially when $\mathrm{FH}$ was not compatible with LMP (median 17 days; 95\% CI 1 - 44). The error was worse for the clinical GA compared with the final GA estimation (median 12 days; 95\% CI 1 - $46 \mathrm{v}$.

Table 2. Incidence of pre- and post-term delivery, small- and large-for-gestational age infants in women scanned by US before or after 24 weeks or not scanned

\begin{tabular}{|c|c|c|c|}
\hline & $\begin{array}{l}\text { Total } \\
n(\%) \\
\end{array}$ & $p$-value & $\begin{array}{l}\text { OR } \\
(95 \% \mathrm{CI})\end{array}$ \\
\hline Known delivery date & $1185(88.3)$ & & \\
\hline Delivery $<37$ weeks ${ }^{*}$ & $177 / 1185(14.9)$ & & \\
\hline US-GA $<168$ days & $85 / 709(12.0)$ & $<0.001^{\ddagger}$ & $0.47(0.32-0.68)$ \\
\hline US-GA $\geq 168$ days & $26 / 183(14.2)$ & $0.03^{\ddagger}$ & $0.57(0.34-0.96)$ \\
\hline No scan & $66 / 293(22.5)$ & & \\
\hline Delivery $\geq 42$ weeks & $105 / 1185(8.9)$ & & \\
\hline US-GA $<168$ days & $36 / 709(5.1)$ & $<0.001^{\ddagger}$ & $0.20(0.12-0.31)$ \\
\hline US-GA $\geq 168$ days & $6 / 183(3.3)$ & $<0.001^{\ddagger}$ & $0.12(0.05-0.31)$ \\
\hline No scan & $63 / 293(21.5)$ & & \\
\hline Known birth weight & $1182(88.1)$ & & \\
\hline Small-for-GA ${ }^{\dagger}$ & $142(12.0)$ & & \\
\hline US-GA $<168$ days & $107 / 707(15.1)$ & & \\
\hline US-GA $\geq 168$ days & $13 / 183(7.1)$ & $0.005^{\varsigma}$ & $2.33(1.24-4.46)$ \\
\hline No scan & $22 / 292(7.5)$ & $0.001^{\S}$ & $2.19(1.32-3.65)$ \\
\hline Large-for- $\mathrm{GA}^{\dagger}$ & $149(12.6)$ & & \\
\hline US-GA $<168$ days & $42 / 707(5.9)$ & $<0.001^{\ddagger}$ & $0.39(0.24-0.62)$ \\
\hline US-GA $\geq 168$ days & $12 / 183(6.6)$ & $0.01^{\ddagger}$ & $0.43(0.21-0.88)$ \\
\hline No scan & $41 / 292(14.1)$ & & \\
\hline \multicolumn{4}{|c|}{$\begin{array}{l}\text { US = ultrasound; } \mathrm{OR}=\text { odds ratio; } \mathrm{CI}=\text { confidence interval; } \mathrm{GA}=\text { gestational age. } \\
* \text { Women with known delivery date. } \\
\text { "Infants with known birth weight. } \\
\text { "Compared with women not scanned. } \\
\text { "Compared with women scanned }<168 \text { days ( } 24 \text { weeks). }\end{array}$} \\
\hline
\end{tabular}


median 8 days; 95\% CI 1 - 33; $p<0.001$ ) even when LMP and FH seemed compatible with one another (median 11 days; 95\% CI 1 - 43).

The absolute difference between US-based EDD and ADD increased with advancing US-based GA. US-based dating performed best before 20 weeks (median 6 days; 95\% CI 0 - 19; $p<0.005)$ and worst after 30 weeks (median 10.5 days; 95\% CI 1 - 29) but was similar at 20 - 24 weeks (median 7 days; 95\% CI 0 - 22) and at 24 - 30 weeks (median 9 days; 95\% CI 1 - 22; $p=0.07$ ). Final EDD prediction was similar for all dating where US was involved, whether the LMP tolerance intervals were allowed or not. Final EDD prediction was significantly worse in the absence of US, independent of whether either the LMP or FH were used as the single dating method. Prediction of ADD within short intervals was better with LMP than with FH (Fig. 2); a certain LMP date was not, however, more accurate than an uncertain one (Fig. 3). Prediction was significantly better for final GA, than clinical estimation but was best with US only (particularly if undertaken before 20 weeks) (Figs 2 and 3). When US contributed to the final dating (either confirming or refuting the LMP), the OR for spontaneous onset of labour within 14 days of EDD was 5.80 (95\% CI 4.08 - 8.25) when compared with dating based on the LMP and/or FH only $(p<0.001)$.

\section{Discussion}

This study was performed in a low-resource setting where, according to current provincial policy, only women clinically $<24$ weeks pregnant routinely have access to US. For women who book later, comprising approximately one-third of this study population, pregnancy dating relies entirely on clinical assessment for which there exists a published guideline that is widely taught, promoted and used throughout SA. The current intervention provided the opportunity to test the accuracy of this guideline since the 2nd arm of the study enabled all women to access US services, irrespective of their GA at time of booking. The chief result of our analysis was that US-based dating is more accurate in predicting spontaneous labour than the LMP and FH, either alone or in combination.

As expected, ${ }^{[1,12]}$ the LMP was uncertain in $44 \%$ of cases and considerably different from the US-based GA $37.0 \%$ of cases when the LMP was certain and $48.8 \%$ of cases when uncertain). These discrepancies are worse than those reported from affluent countries or research settings in other resource-poor areas, ${ }^{[1,7,12,19]}$ but consistent with previous results in the SA population. ${ }^{[15]}$ LMP-EDD had the largest absolute error and wide CIs. This finding was comparable to one study, ${ }^{[19]}$ but less so to others. ${ }^{[11,12]}$. This may be related to poor history-taking ${ }^{[1]}$ or a high incidence of late presentation and unplanned pregnancies. ${ }^{[20,21]}$ The LMP-based dating was most likely to result in overestimation of the true GA as has been shown previously. ${ }^{[22]}$ US-based dating more often refuted, rather than confirmed, the LMP-based GA. Large over-and underestimations ${ }^{[1,11,12]}$ could not be anticipated from the history of the LMP but were often suspected clinically.

First FH-based GA was compatible with the LMP-based GA in $69.5 \%$ of women and with US-based dating in $83.8 \%$, which is worse than found by others, ${ }^{[19]}$ but

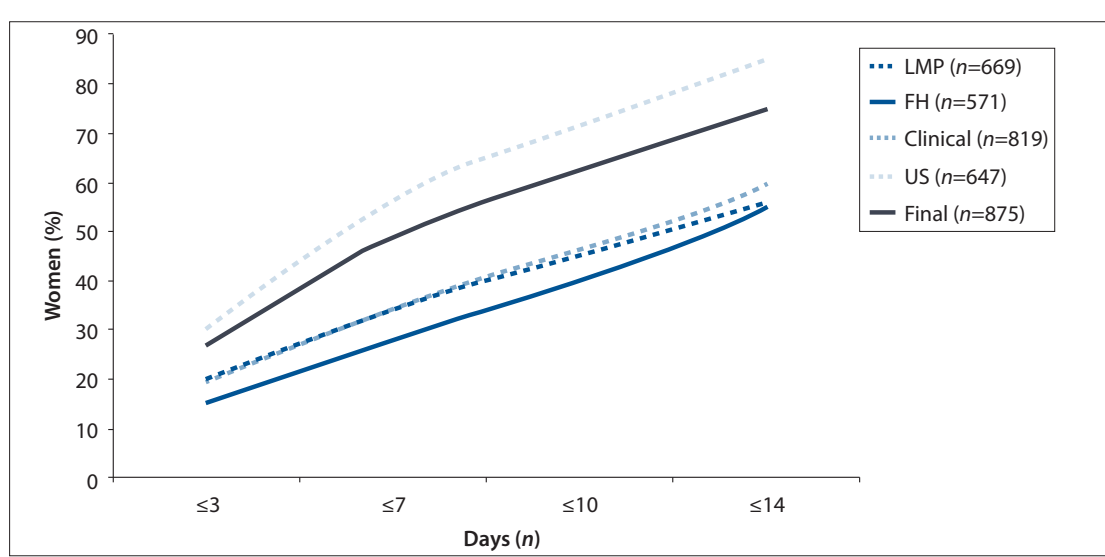

Fig 2. Percentage of women delivering within 14 days of the delivery date predicted by the different dating methods with known date of delivery, spontaneous onset of labour and $B W \geq 2500 \mathrm{~g}$. (For US v. LMP, FH and clinical for all time intervals, $\mathrm{p}<0.005$; for US $v$. final for $\geq 3$ days, $\mathrm{p}<0.005$; for final v. LMP, FH and clinical for all intervals, $\mathrm{p}<0.05$; for FH v. LMP or clinical for intervals upto 7 days, $\mathrm{p}<0.05$.)

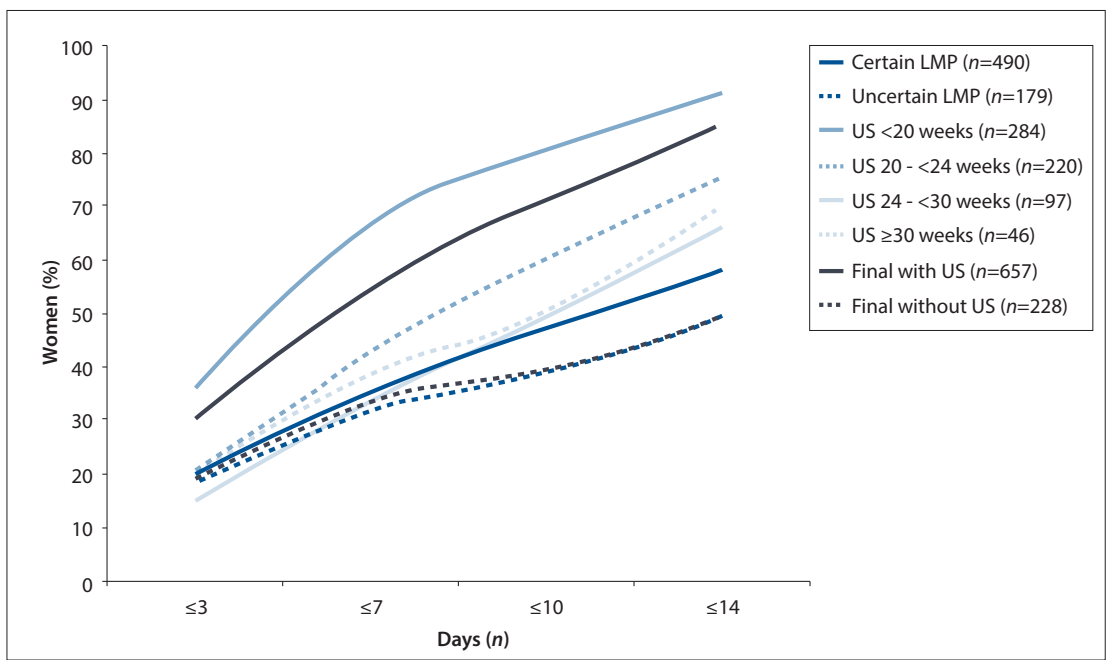

Fig 3. Percentage of women delivering within 14 days of the delivery date predicted by the different dating methods, with known date of delivery, spontaneous onset of labour and $B W \geq 2500 \mathrm{~g}$. (For US $<20$ weeks $v$. later US and LMP for all time intervals, $\mathrm{p}<0.05$; for US $<20$ weeks $v$. final with US for $>3$ days, $\mathrm{p}<0.05$ and $v .<3$ days, $\mathrm{p}=0.06$; for final with US $v$. final without US for all time intervals, $\mathrm{p}<0.05$; for certain $L M P$ v. uncertain LMP for all intervals, $\mathrm{p}>0.05$.) 
lower BMIs and not dissimilar to those that employed a multiple FH-measures model. ${ }^{[5,6,19]}$

Clinical estimation of GA according to the recommended guideline, i.e. using certain LMP-based GA with defined tolerance intervals for FH-based GA, lead to wide CIs and appeared to perform best when it was based on the LMP rather than FH. However, of 679 women for whom LMP-based GA was chosen, FH-based GA was compatible for 450. FH data to assess the validity of the LMP-based GA were lacking in the remainder. It is plausible, therefore, that the clinical estimation might have fared better if $\mathrm{FH}$ had been more consistently measured prior to US. Our data, however, illustrate the difficulty in choosing between the LMP-based and FH-based GA when there is absence of concurrence, unless the difference is very large and the LMP-based GA cannot possibly be correct. Since FH-based dating generally performed worse than LMP-based dating, a larger tolerance interval may need to be considered before refuting a certain LMP-based GA.

As previously noted, ${ }^{[1,11,12]}$ US had the smallest absolute error and narrowest distribution despite including patients (22.1\%) who underwent late US ${ }^{[13,14]}$ and relying on European sample-based biometry reference ranges generated for assessment of fetal growth rather than GA. Our results (57\% of deliveries within 7 days and $85 \%$ within 14 days; $95 \%$ CI -11 - 21) were in keeping with other studies that used dating formulae based on early or mid-gestation US, ${ }^{[1,9,11,14,19]}$ in line with the limited biological variability in early fetal biometry and reports of better dating with 1st trimester US. ${ }^{[24]}$ The absolute error and close ADD prediction of US dating between 20 and 24 weeks was comparable to US dating $>24$ weeks, but was significantly better if done $<20$ weeks. With the current provincial US policy, scans $<18$ weeks represent only one tenth of all US, while most 1 st scans are performed between 20 and 24 weeks (despite the recommendation of $18-20$ weeks as the optimal time). An assessment of whether US-based dating $>20$ weeks in this population can be improved upon by using validated population-based dating formulae, ${ }^{[12,25]}$ or dating formulae designed for late US, ${ }^{[13,14]}$ may prove worthwhile. Moreover, this may be more efficient than increasing the number of early US examinations by offering a booking scan for all women -the associated significant increase in US workload ${ }^{[16]}$ is currently not affordable in SA's public health service.

Incorporating US information, according to the published guideline, significantly improved the accuracy of final ADD prediction (from $27 \%$ to $42 \%$ compared with clinical prediction) and resulted in much narrower CIs (improved from $-35 /+35$ to $-17 /+27$ days). Allowing tolerance intervals for US did not result in better final dating compared with US alone, but final dating was substantially better when based on US (with or without the LMP) rather than on the LMP or FH alone. Even though a substantial proportion of dating scans were done after 24 weeks, post-term deliveries occurred in only $4.7 \%$ of all scanned women (Table 2), close to what is typically seen with early US dating. ${ }^{[11,12]}$ Absence of US created significant clinical dilemmas due to over-and under-estimations of GA based on the LMP and FH, ${ }^{[1,11,22]}$ leading to higher than expected incidences of assumed post-and preterm deliveries and LGA infants. The incidence of SGA infants in women who were either not scanned, or who were scanned late, was half that after early US dating ( $7.4 \%$ v. $15.1 \% ; p<0.001)$, suggesting that the absence of early US may lead to an underestimate of the problem of growth restriction, which is an important contributor to adverse perinatal outcome.

\section{Conclusion}

As US-based dating did not perform worse than allowing a tolerance interval for the LMP, consideration should be given to dating by US alone, at least when done early and by experienced sonographers.
Because US pregnancy dating $>24$ weeks was superior to the LMPand FH-based methods, and not much worse than US done at 20 - 24 weeks, routine US-based GA dating for women presenting later than the current cut-off of 24 weeks has merit. The accuracy of US $>20$ weeks, however, was significantly worse than $<20$ weeks, demanding that other solutions such as the use of specific dating formulae need to be explored to improve US dating at later gestations. FH-based dating cannot be trusted in the morbidly obese. When the LMP and FH are not compatible, the error of clinical GA estimation is very substantial. Caution is advised especially when making clinical decisions regarding assumed pre- or post-term pregnancies and when risk factors for growth restriction exist.

This study shows that in a resource-poor area where late presentation, unreliable LMP history (taking) and obesity are common, dating with US was significantly better than a reliance on clinical methods, even when certain LMP appeared to be compatible with $\mathrm{FH}$.

\section{References}

1. Geirsson RT. Ultrasound instead of last menstrual period as the basis of gestational age assignment. Ultrasound Obstet Gynecol 1991;1(3):212-219. [http://dx.doi.org/10.1046/j.1469-0705.1991.01030212]

2. Bagger PV, Sindberg Eriksen P, Secher NJ, Thisted J, Westergaard L. The precision and accuracy of symphysis-fundus distance measurements during pregnancy. Acta Obstet Gynecol Scand 1985;64(5):371-374. [http://dx.doi.org/10.3109/00016348509155150]

3. Mongelli M, Gardosi J. Symphysis-fundus height and pregnancy characteristics in ultrasound-dated Mongelli M, Gardosi J. Symphysis-fundus height and pregnancy characteristics in ultrasound-dated pregnancies. Obstet Gynecol 1999;94(4):591-594. [http://dx.doi.org/10.1016/S0029-7844(99)00380-4] Thompson ML, Theron GB, Fatti LP. Predictive value of conditional centile charts for weight and fundal height in pregnancy in detecting light for gestational age births. Eur J Obstet Gynecol Reprod
Biol 1997;72(1):3-8. [http://dx.doi.org/10.1016/S0301-2115(96)02643-7]

. White L, Lee SS, Stepniewska K, et al. Estimation of gestational age from fundal height: A solution for resource-poor settings. J R Soc Interface 2012;9(68):503-510. [http://dx.doi.org/10.1098/rsif.2011.0376] 6. Andersson R, Bergström S. Use of fundal height as a proxy for length of gestation in rural Africa. J Trop Med \& Hyg 1995;98(3):169-172.

7. Neufeld LM, Haas JD, Grajéda R, Martorell R. Last menstrual period provides the best estimate of gestation length for women in rural Guatemala. Paediatr Perinat Epidemiol 2006;20(4):290-298. [http://dx.doi.org/10.1111/j.1365-3016.2006.00741.x]

8. Perni SC, Chervenak FA, Kalish RB, et al. Intraobserver and interobserver reproducibility of fetal biometry. Ultrasound Obstet Gynecol 2004;24(6):654-658. [http://dx.doi.org/10.1002/uog.1717]

9. Tunón K, Eik-Nes SH, Grøttum P. The impact of fetal, maternal and external factors on prediction of the day of delivery by the use of ultrasound. Ultrasound Obstet Gynecol 1998;11(2):99-103. [http:// dx.doi.org/10.1046/j.1469-0705.1998.11020099.x]

10. American College of Obstetricians and Gynecologists. ACOG Practice Bulletin No. 101: Ultrasonography American College of Obstetricians and Gynecologists. ACOG Practice Bulletin No. 101: Ultrasonography
in pregnancy. Obstet Gynecol 2009;113(2):451-461. [http://dx.doi.org/10.1097/AOG.0b013e31819930b0]

1. Mongelli M, Wilcox M, Gardosi J. Estimating the date of confinement: Ultrasonographic biometry versus certain menstrual dates. Am J Obstet Gynecol 1996;174(1):278-281. [http://dx.doi.org/10.1016/S0002certain menstrual

12. Tunón K, Eik-Nes SH, Grøttum P. A comparison between ultrasound and a reliable last menstrual period as predictors of the day of delivery in 15000 examinations. Ultrasound Obstet Gynecol 1996;8(3):178-185. [http://dx.doi.org/10.1046/j.1469-0705.1996.08030178.x]

13. Mongelli M, Chew S, Yuxin NG, Biswas A. Third-trimester ultrasound dating algorithms derived from pregnancies conceived with artificial reproductive techniques. Ultrasound Obstet Gynecol 2005;26(2):129-131. [http://dx.doi.org/10.1002/uog.1939]

14. Mongelli M, Yuxin NG, Biswas A, Chew S. Accuracy of ultrasound dating formulae in the late secondtrimester in pregnancies conceived with in-vitro fertilization. Acta Radiol 2003;44(4):452-455. [http:// dx.doi.org/10.1034/j.1600-0455.2003.00089.x]

15. Geerts L, Theron AM, Grove D, Theron GB, Odendaal HJ. A community-based obstetric ultrasound service. Int J Gynecol Obstet 2004;84(1):23-31. [http://dx.doi.org/10.1016/S0020-7292(03)00310-2]

6. Poggenpoel EJ, Geerts LTGM, Theron GB. The value of adding a universal booking scan to an existing poggenpoel EJ, Geerts LTGM, Theron GB. The value of adding a universal booking scan to an existing
protocol of routine mid-gestation ultrasound scan. Int J Gynecol Obstet 2012;116(3):201-205. [http:// protocol of routine mid-gestation ultras
dx.doi.org/10.1016/j.ijgo.2011.10.027]

17. Perinatal Education Programme. Maternal Care Manual. Cape Town: Electric Book Works, 2010:20-21.

18. Theron GB, Thompson ML. A centile chart for birth weight for an urban population of the Western Cape. S Afr Med J 1995;85(12):1289-1292

19. Jehan I, Zaidi S, Rizvi S, et al. Dating gestational age by last menstrual period, symphysis-fundal height, and ultrasound in urban Pakistan. Int J Gynaecol Obstet 2010;110(3):231-234. [http://dx.doi. org/10.1016/j.ijgo.2010.03.030]

20. Solarin I, Black V. 'They Told Me to Come Back: Women's antenatal care booking experience in inner-city Johannesburg. Matern Child Health J 2013;17(2):359-367. [http://dx.doi.org/10.1007/s10995-012-1019-6]

21. Hubacher D, Mavranezouli I, McGinn E. Unintended pregnancy in sub-Saharan Africa: Magnitude of the problem and potential role of contraceptive implants to alleviate it. Contraception 2008;78(1):7378. [http://dx.doi.org/10.1016/j.contraception.2008.03.002]

22. Gardosi J, Vanner T, Francis A. Gestational age and induction of labour for prolonged pregnancy. Br J Obstet Gynaecol 1997;104(7):792-797. [http://dx.doi.org/10.1111/j.1471-0528.1997.tb12022.x]
. Gardosi Vanner T, Francis A. Gestational age and induction of labour for prolonged pregnan

23. Stuart JM, Healy TJ, Sutton M, Swingler GR. Symphysis-fundus measurements in screening for small. Stuart JM, Healy TJ, Sutton M, Swinger GR. Symphysis-fundus measurements in screening for small-
for-dates infants: A community based study in Gloucestershire. J R Coll Gen Pract 1989;39(319):45-48.

4. Salomon LJ, Pizzi C, Gasparrini A, Bernard JP, Ville Y. Prediction of the date of delivery based on first trimester ultrasound measurements: An independent method from estimated date of conception. J trimester ultrasound measurements: An independent method from estimated date of concep
Matern Fetal Neonatal Med 2010;23(1):1-9. [http://dx.doi.org/10.3109/14767050903078672]

25. Okland I, Gjessing HK, Grøttum P, Eggebø TM, Eik-Nes SH. A new population-based term prediction model vs. two traditional sample-based models: validation on 9046 ultrasound examinations. Ultrasound Obstet Gynecol 2011;37(2):207-213. [http://dx.doi.org/10.1002/uog.7728] 